\title{
The Stigma And Discrimination Faced By The People Living With HIV And Aids
}

\section{Manna Ghazanfar Ali}

Women's Studies

University of Karachi

\begin{abstract}
Gender equality is central to realizing the country's agenda, which risks failure without the full involvement of all members of society. But as it fails in many countries all over the world, the peril in different targeted areas have been increased. So is the case of sexually transmitted infections. The major risks are seen in the field of HIV/Aids. At present South Asia is combating a battle against HIV/Aids. Pakistan is the second largest country in South Asia and it stands only a few steps behind India and Nepal in terms of HIV epidemic. The aim of this paper is to give the people living with HIV and AIDS a platform to raise a common voice for their rights and to contribute to the national response by spreading awareness. The paper also intends the participation of the people, through encouragement, policy education and prevention, which can strive to minimize the adverse personal and social effects of stigma and discrimination towards Positive people.
\end{abstract}

تلخيص المقالم

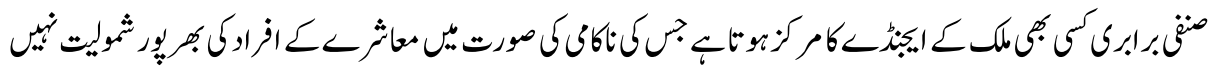

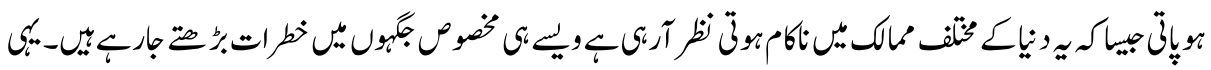

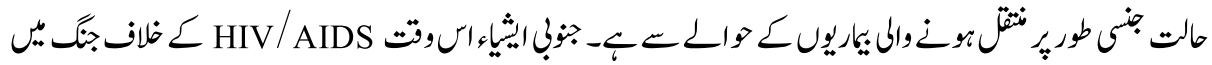

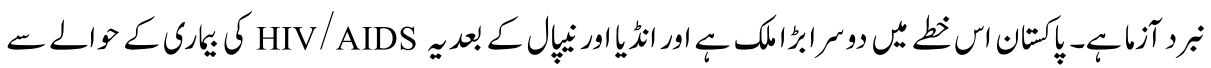

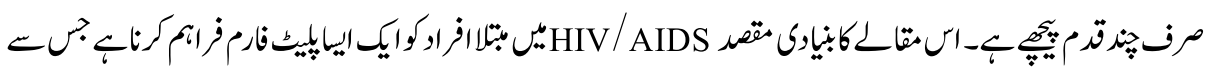

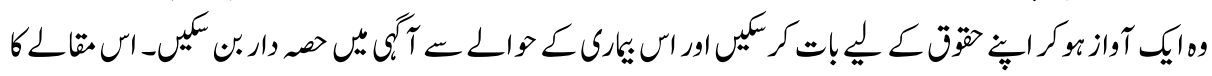

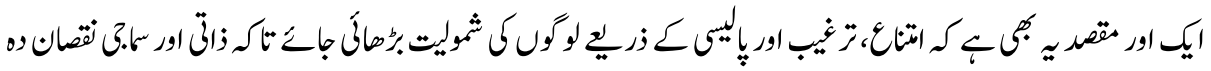

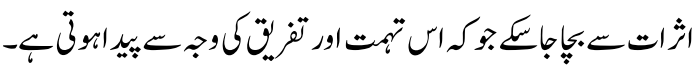

\section{Introduction}

HIV related stigma and discrimination ${ }^{1}$ are widely recognized as barriers to admittance HIV treatment and care services. Without addressing and reducing stigma, the goal of universal access will be impossible to achieve. Much of what we know about the stigma 
attached to HIV is untrustworthy or patchy and does not always include the perspective of people living with HIV.

\section{Statistics}

By 2007 the total population of Pakistan is estimated to be about 164.74 million with the average annual intercensal growth rate at $1.87 \%$ per annum estimates for 2005 (NACP 2006-07), which places it at sixth among the most populous nations in the world. Of the total population only $30 \%$ resides in urban areas whereas the rest is rural population with limited access to health services. The first HIV positive Pakistani was identified in 1987 and since then an increasing number of positive individuals have been reported to the National AIDS Control Program. Currently an estimated 85,000 people are living with HIV/AIDS in the country with the HIV prevalence less than $1 \%$ in overall population. Although estimates for PLWHA $^{2}$ and prevalence of HIV in general population has remained fairly constant over the years, there has been a shift from low prevalence to a concentrated epidemic due to rapid rise of infections among core risk groups in particular the injecting drug users in some cities.(Federal Bureau of Statistics, 2007)

Pakistan is a geographically huge, ethnically diverse country with a population of approximately 160 million people. Official HIV statistics published by UNAIDS give the number of people living with HIV as 85,000 , with a prevalence rate of between 0.01 and $0.02 \%$.( UNAIDS). These rates are based on the number of reported cases currently 3,800 since the first case was identified in 1986. However, the World Health Organization (WHO) as well as UNAIDS put the real number at around 200,000.(IRIN report)

There is no surveillance system across the general population, but data collected on the prevalence in high-risk groups is startling. The high- risk groups include $\mathrm{IDUs}^{3}, \mathrm{MSW}^{4}$, FSW $^{5}$ and Hijras ${ }^{6}$. Evidence from surveillance round of 2005 and 2007 indicate that there are substantial and widespread networks of vulnerable key populations at high risk of acquiring HIV, particularly IDUs and commercial sex workers which includes female, male and hijra. (NACP,2006-07).

Among reported infections, heterosexual sex is the primary mode of transmission accounting for 67 percent of infections, followed by contaminated blood and blood products 18 percent, homosexual or bisexual sex 6 percent, injecting drug use 4 percent, and mother-to-child transmission 1.3 percent, (UNAIDS-2006). However, research shows an alarming spike in HIV prevalence in urban IDUs. The percentage of HIV infections among Karachi IDUs increased drastically between January 2003 and March 2005 from 0.4 percent to 26 percent. In mid-2005, HIV prevalence among IDUs was 12 percent in Sargodha, 9.5 percent in Faisalabad, 24 percent in Quetta, and 8 percent in Larkana. A study among IDUs in Karachi and Rawalpindi found only about half knew HIV could be 
transmitted through sharing of unclean needles. The Ministry of Health found that 48 percent of IDUs in Karachi and 82 percent in Lahore had used non-sterile syringes in the week before a 2004 survey. Twenty-one percent of IDUs in Karachi and 51 percent in Lahore had injected in another city during the previous year. HIV prevalence is considerably lower among other groups at risk of infection. Among FSWs in Karachi, HIV prevalence was 2 percent, while it was below 1 percent in Lahore and Rawalpindi. Lack of knowledge, unsafe practices, and high mobility are the likely drivers of this phenomenon. (USAID)

Pakistan has a high tuberculosis (TB) burden, with 82 new cases per 100,000 people in 2005, according to the World Health Organization. HIV infects only 0.6 percent of adults with TB. However, increased rates of HIV-TB co-infection would complicate treatment and care for both diseases.

\section{HIV among Male Sex Workers and Transgender}

Despite various preventive efforts, the infection rates among IDUs have steadily increased from $10.8 \% 262 \mathrm{HIV}+$ ve out of 1779 tested in 2005 to nearly $21 \% 618 \mathrm{HIV}$ +ve out of 2969 tested in 2008. (NACP,2008)

Surveillance data for 2006 point to a local concentrated epidemic among MSWs and Hijras in Larkana and Karachi in the Sindh province while prevalence elsewhere is still below 5 percent. Behavioral surveillance data for 2005 indicates very low levels of condom use among MSWs and transgender across all cities surveyed. One in four of the male sex workers said they also bought or sold sex to women. Such high-risk behavior must be addressed in order to limit the further spread of HIV in and beyond those sexual networks.

The HIV epidemic in Pakistan is presently concentrated in the Injecting Drug Users (IDUs) population and has reached upto $51 \%$ in certain urban areas. There is also indication of rising infections among the MSW (Hijras) population which is more visible in cities that have had an established IDU epidemic since 2-3 yrs. This is an alarming situation and a clear signal for urgent and focused actions in reducing rapid spillover of infection from these core groups to others and thereby to the general population.

The overall, sero-prevalence among MSWs was $0.9 \%$ 95\% CI: $0.3 \%, 1.5 \%$. Seroprevalence was highest among MSWs in Karachi 3.1\%. No MSW tested positive for HIV in Hyderabad, Faisalabad and Peshawar.(NACP, 2008)

\section{Unsafe Practices among Female Sex Workers}

Coming to the female sex workers, the results are also raising due to unsafe practices among female sex workers. Commercial sex is prevalent in major cities and on truck 
routes. Behavioral and Mapping studies in three large cities found a sex worker population of 100,000 with limited understanding of safe sexual practices. Condom use is still low during commercial sex encounters although consistent condom use is more prevalent in Karachi and Lahore where targeted interventions were initiated in 2004. Only 4 Percent of male sex workers and less than 1 percent of the hijras in a Karachi study said they used a condom the last time they had sex with a man. Furthermore, sex workers often lack the power to negotiate safe sex or seek treatment for STIs because they are stigmatized. High levels of sexually transmitted infections indicate widespread sexual risk taking. (Association of people living with HIV and Aids).

\section{Low Levels of Literacy and Education}

Efforts to increase awareness about HIV among the general population are hampered by low literacy levels and cultural influences whereby HIV is associated with extra marital sex which is an abomination in the Muslim culture hence high level of Stigma and discrimination. In 2006, female literacy was estimated at 42 percent. Misconceptions and lake of knowledge of media \& some religion leaders on the disease has accelerated negative attitudes towards PLHIVs. This is not benefiting the low levels of education \& literacy level as it relates to HIV/AIDS. (Association of people living with HIV and Aids).

This reinforces the importance of NACP and PACP's plans to rapidly scale up focused prevention to limit the growth of the HIV epidemic in these populations, thereby reducing the overall size of the HIV epidemic. This is particularly important considering the overlap between IDU populations and high risk sexual networks apparent in many of the cities. The rising HIV prevalence among IDUs will increase the risk of spill-over into the large high risk sexual networks of commercial sex workers and their clients.

\section{Forms of Stigma}

There are a number of organizations that are campaigning against stigma and discrimination and fighting for improved rights for people living with HIV. The targeted population estimated in the year 2008 was approximately 4,000 reported cases and 800 registered with treatment centers \& with NGOs. (Association of people living with HIV and Aids).

Stigma and discrimination is a huge problem in the fight against HIV \& AIDS in Pakistan. The small number of people who are public about their status report that they are ostracized and abhorred by their neighbors and friends. (IRIN report). The actual prevalence rates are therefore very hard to determine, but there is strong consensus that Pakistan is at a very high risk of the virus spreading. 
The above giving studies have shown that people living with HIV often face stigma and discrimination. Many do not know what their rights are and how they can help to change things for the better. The following table classifies the different kinds of stigma and discrimination statuses faced by the positive people.

Figure 1 The link between HIVIAIDS and pre-existing sources of S\&D

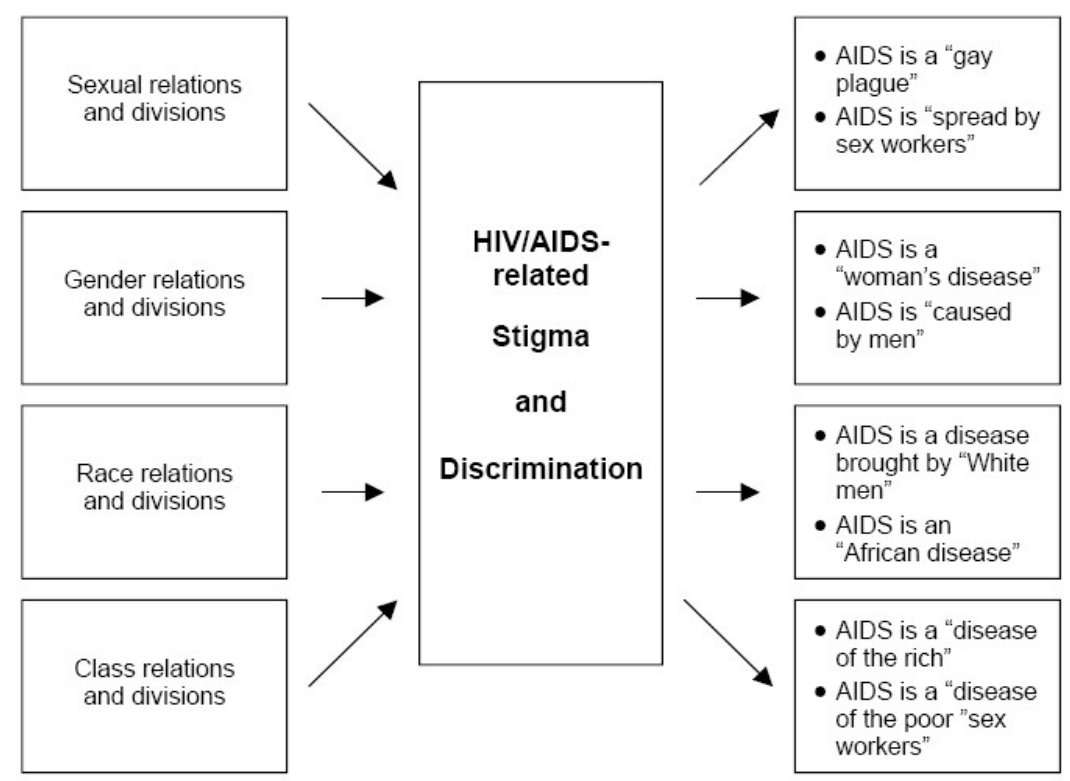

Source: http://www.populationcouncil.com/pdfs/horizons/sdcncptlfrmwrk.pdf

\section{Conclusion}

It is therefore needed to build the evidence base for understanding the stigma and discrimination experienced by the people living with HIV in different countries. Increased involvement and sharing can be used by the government to support the rights, freedom and laws for the people living with HIV.

\section{End Notes}

1 Stigma and Discrimination related to HIV/Aids: To understand the ways in which HIV/AIDS-related S\&D appear and the contexts in which they occur, we first need to understand how they interact with pre-existing S\&D associated with sexuality, gender, race, and poverty. HIV/AIDS-related S\&D also interact with preexisting fears about contagion and disease. Early AIDS metaphors - as death, as horror, as punishment, as guilt, as shame, as otherness - have exacerbated these fears, reinforcing and legitimizing stigmatization and discrimination. The S\&D related to HIV/Aids includes sexuality, gender, race and ethnicity, class and fear of contagion and disease. Attawell, 
Kathy, Pulerwitz, Julie, \& Brown Lisanne (May, 2002) HIV/AIDS-related Stigma and Discrimination: A Conceptual Framework and an Agenda for Action, The Population Council, NY, USA, pp 1,2,3,4.

${ }^{2}$ People Living with HIV/Aids

${ }^{3}$ Injecting drug user (IDU): There are several ways of using drugs, and one way is through injecting. In HIV work, the term "injecting drug use" describes the behaviour of someone who injects drugs. Injecting drug users face the same sex-related risks of HIV as other people, and those who share contaminated drug injecting equipment (such as a needle or a syringe) are at an additional risk of acquiring HIV through the use of contaminated drug equipment.

http://www.ippf.org/en/What-we-do/AIDS+and+HIV/UK+Stigma+Index+poster.htm Retrieved on $9^{\text {th }}$ July, 2009.

${ }^{4}$ Men who have sex with men (MSM): This is a term that refers to the behavior of men who have sex with other men. It is a term that recognizes that some men who have sex with men also have sex with female partners and that men who have sex with other men may not necessarily identify as "gay", "homosexual" or "bisexual" - all of which are examples of categories of sexual orientation and identity. Men who have sex with men often face a double stigma because they are marginalized for their sexual behavior and seen as part of a group that is associated with being at particular risk for HIV infection. http://www.ippf.org/en/What-we-do/AIDS+and+HIV/UK+Stigma+Index+poster.htm Retrieved on $9^{\text {th }}$ July, 2009.

${ }^{5}$ FSW: Female sew workers, the term is used to describe a woman who engages in sexual activity for payment.

http://www.ippf.org/en/What-we-do/AIDS+and+HIV/UK+Stigma+Index+poster.htm Retrieved on $9^{\text {th }}$ July, 2009.

${ }^{6}$ Hijras or transgender is an umbrella term that includes transsexuals and transvestites. A transsexual is someone who may be born biologically male, yet has a female gender identity or be born a female and yet define themselves as a man. A transvestite is a man who likes to wear female clothes and adopt traditionally female characteristics. $<$ www.ippf.org $>$. http://www.ippf.org/en/What-we-do/AIDS+and+HIV/UK+Stigma+Index+poster.htm Retrieved on $9^{\text {th }}$ July, 2009.

\section{References}

UNAIDS 2006 Report on the Global AIDS Epidemic.

IRIN report, (May 2007) HIV/AIDS will not go away if you ignore it, Retrieved On $10^{\text {th }}$ July, 2009, www.irinnews.org/Report.aspx?ReportId=72164. 
IRIN report Pakistan, (September 2007) Special on living with HIV/AIDS, Retrieved on $10^{\text {th }}$ July, 2009

www.irinnews.org/InDepthMain.aspx?InDepthId=39\&ReportId=70955\&Country $=\underline{\text { Yes }}$

UNGASS Pakistan Report (2007) Progress Report on the Declaration of Commitment on HIV/AIDS For United Nations General Assembly Special Session on HIV/AIDS, National AIDS Control Program, Ministry of Health, Government of Pakistan, Islamabad.

HIV Second Generation Surveillance in Pakistan, National Report Round III(2008)

National AIDS Control Programme, Ministry of Health, Pakistan, CanadaPakistan HIV/AIDS Surveillance Project.

NACP (2006-07) HIV Second Generation Surveillance in Pakistan, National Round 2 Report, National AIDS Control Programme, Ministry of Health, Islamabad, Pakistan.

Federal Bureau of Statistics estimates (2007) Pakistan. www.usaid.gov/pk/

Manna Ghazanfar Ali is student of M.A at Centre of Excellence for Women's Studies, University of Karachi. 